BOOK REVIEWS

Vertebrate Past
Vertebrate Palaeozoology. By
Everett C. Olson. Pp. xiii +839 .
(Wiley Interscience: New York and
London, May 1971.) $£ 14.25$.

IT is rare-and highly refreshing-to find a textbook in any subject which makes a completely new approach. This Professor Olson has achieved. The conventional textbook tells the reader what is known; where diffculties arise they are glossed over or sometimes ignored altogether. The intention is to produce a self-contained synthesis which gives the student a clear and intellectually satisfying picture of the basic structure-and the excellence of the textbook varies inversely with the number of inconvenient facts omitted.

Vertebrate Palaeozoology has a different aim and follows a different pattern. The author sets out to give an overall picture of the present state of the science, to relate the animal to its environment and to clothe the hard parts in living flesh. But a much more significant and valuable innovation is that we are spared none of the diffculties, rather are they carefully spelled out for us. Thus the man who is teaching in any branch of vertebrate palaeontology can get an up to date picture of the state of knowledge in that field, and, what is perhaps more important, the certainty of that knowledge. The research worker can see how work is progressing in fields related to his own, and can perhaps find it valuable in suggesting research problems for his graduate students. Most valuable of all, however, the student can really see what scienceas exemplified by vertebrate palaeontology-is all about-how it consists at any time of a mass of facts: some connected reasonably firmly by theory, some strung together by tentative and rather unsatisfactory hypotheses and some just sticking out like sore thumbs and refusing to fit in comfortably anywhere. As pedagogic methods change and student studies increasingly range more widely and, as an inevitable concomitant, become shallower, the experience of being asked a question by a student, answering honestly "I do not know" and seeing the look of outraged horror on his face, will become commoner. Professor Olson's book is a useful corrective to students falling into the error that either their teachers or their textbooks embrace, in their own field, the whole of knowledge.
The book is divided into four sections. The first deals with the history of the Vertebrata in broad outline and in a rather summary manner-it is short (52 pages). The second section is entitled "Vertebrate Morphology and Function"; it is larger (114 pages); and its scope is adequately illustrated by its title. The third section is considerably longer than either of the first two (262 pages) and is entitled "The Classification of the Vertebrates". This covers rather more than is suggested by the title of the section, and includes a considerable amount on the phylogenies of the taxa.

The last section is the longest of all (385 pages) and deals in detail with five special topics: the problems of life in water, the radiation of the Actinopterygii, the conquest of land, the origins of the Mammalia and the influence of palaeogeography on evolution. This section inevitably overlaps to some extent with the one that precedes it. The book is well illustrated but has no plates.

The only major criticism of the book is its price: $£ 14.25$ is ridiculous for such a book and ensures that its only purchasers will be libraries and the more affluent senior workers. This is a pity, as it would be invaluable for teaching graduate students and undergraduates taking advanced courses; and at a more realistic price it could well be prescribed as a class textbook. K. A. Kermack

\section{Travels of Banks}

Joseph Banks in Newfoundland and Labrador, 1766. His Diary, Manuscripts and Collections. By A. M. Lysaght. Pp. $512+103$ plates. (Faber and Faber: London, August 1971.) $£ 15$.

THE name of Joseph Banks is most familiar as the associate of James Cook on his epic voyage around the world in the Endeavour (1768-71), and since the bicentenary celebrations in Britain and Australia this connexion has been many times reinforced. Banks's part in that voyage has to some extent been misinterpreted by later commentators who have represented him as the gentleman amateur, a dilettante naturalist of wide interests but little application. In other eyes Banks was the organizing genius and employer of a well chosen band of scientists and illustrators whose contribution to natural history would have been profound had not sickness and death broken up his team on the return journey.
That Banks made a voyage to Newfoundland and Labrador in 1766 is little known, and in many ways this cruise on the Niger was a rehearsal for the later Endeavour voyage. There is no doubt that it furthered his interest and competence in natural history and set a standard of biological exploration which was to be maintained throughout his later voyages. In April 1766 Banks and Constantine John Phipps joined the Niger, a 32-gun frigate of 679 tons. They spent the months from May to October in the region between St John's, Newfoundland, and Labrador, collecting, exploring, and studying the local inhabitants, their life, economy, and particularly their operation of the great fisheries there. In these five months (four in fact as Banks was ill for most of July) he collected or recorded 340 species of plants, 91 species of birds, and a number of fishes and invertebrates. In addition he kept a journal of his general activities as well as more detailed botanical and zoological notebooks. This all amounted to a considerable achievement for a young man of 23 on his first expedition, especially in the cramped and rigorous conditions of a naval frigate of 1766 .

Dr Averil Lysaght's book is a scholarly appreciation of Banks's work in this region of North America. She has printed his diary (now in the library of the Royal Geographical Society of Australia, South Australian Branch), the detailed descriptions of animals and a few plants (now in McGill University Library), and a catalogue of the names and localities of the plants (now in the British Museum (Natural History)). Strangely, Banks's journal is a very impersonal affair and the man remains something of an enigma. Nowhere does he allow his feelings to obtrude on the factual statements of the day's activities, and his stay in Lisbon at the end of the journey sounds to have been a dull and uneventful time which impression is, however, shown to be false by the relevant letters and notes. These major manuscripts are supplemented by lists of the animals preserved in spirits or of birds' skins, and other original observations, but the whole is welded together with such a wealth of explanatory notes and biographical detail that there is rarely a question comes to mind that is not already answered in a complete manner elsewhere in the book. Lysaght also sheds some interesting new light on Banks's previous acquaintance with Cook (for it has been claimed that they 